\title{
Asian Americans' Indifference to Black Lives Matter: The Role of Nativity, Belonging and Acknowledgment of Anti-Black Racism
}

\author{
Aggie J. Yellow Horse ${ }^{1, *(\mathbb{C}}$, Karen Kuo ${ }^{1}$, Eleanor K. Seaton ${ }^{2} \mathbb{C}$ and Edward D. Vargas ${ }^{3}$ \\ 1 School of Social Transformation, Arizona State University, Tempe, AZ 85287, USA; Karen.Kuo@asu.edu \\ 2 T. Denny Sanford School of Social and Family Dynamics, Arizona State University, Tempe, AZ 85287, USA; \\ Eleanor.Seaton@asu.edu \\ 3 School of Transborder Studies, Arizona State University, Tempe, AZ 85287, USA; EdwardVargas@asu.edu \\ * Correspondence: ajnoah@asu.edu
}

\section{check for}

updates

Citation: Yellow Horse, Aggie J., Karen Kuo, Eleanor K. Seaton, and Edward D. Vargas. 2021. Asian Americans' Indifference to Black Lives Matter: The Role of Nativity, Belonging and Acknowledgment of Anti-Black Racism. Social Sciences 10: 168. https://doi.org/10.3390/ socsci10050168

Academic Editors: Pawan H. Dhingra and Tanya Golash-Boza

Received: 16 March 2021

Accepted: 4 May 2021

Published: 12 May 2021

Publisher's Note: MDPI stays neutral with regard to jurisdictional claims in published maps and institutional affiliations.

Copyright: (c) 2021 by the authors. Licensee MDPI, Basel, Switzerland. This article is an open access article distributed under the terms and conditions of the Creative Commons Attribution (CC BY) license (https:// creativecommons.org/licenses/by/ $4.0 /)$.

\begin{abstract}
This paper assesses how ongoing historical racism and nativism as embedded within U.S culture requires new and important dialogues about the omnipresence of White supremacy and its interconnected mechanisms that divide communities along the lines of race and perceived in-group status. To assess the role of immigration as it is understood through paradigms of White supremacy and systemic racism, the current study examines individual-level predictors of indifference to the BLM movement based on nativity status among Asian Americans-a racialized pan-ethnic group that is comprised of predominantly foreign-born members. Using the 2016 Collaborative Multiracial Post-Election Survey, one of the few nationally representative surveys that include detailed information about the Black Lives Matter movement, our study includes 1371 Asian immigrants (i.e., foreign-born Asian Americans) and 1635 U.S.-born Asian Americans. Results demonstrate that reporting indifference to the BLM movement differ by nativity such that foreign-born Asian Americans were significantly more likely to report indifference to the BLM movement compared to their U.S.-born Asian American counterparts. However, the impact of nativity disappears once we account for sense of belonging and acknowledgement of anti-Black racism. The sense of belonging was significant in predicting indifference to the BLM movement among U.S.-born Asian Americans only. The findings contribute to our understanding of racial sense making for Asian Americans as well as an understanding of how White supremacy translates to anti-Black racism through multiple and interconnected mechanisms for the maintenance of White supremacy.
\end{abstract}

Keywords: white supremacy; immigration; anti-Blackness; Asian American; belonging

"You cannot change any society unless you take responsibility for it; unless you see yourself as belonging to it and responsible for changing it"

—Grace Lee Boggs (emphasis added)

\section{Introduction}

Fueled by the parallel pandemics of the novel Coronavirus 2019 (COVID-19) and the ongoing police violence and murder of Black people, conversations around historically embedded racism and nativism have resurged in public dialogues to shed light on systematic injustices experienced by racialized and minoritized people. Specifically, these dialogues highlight the role of White supremacy in racism and nativism. The COVID-19 pandemic - a seemingly value-neutral health emergency - has shaken public dialogues on White supremacy in at least three substantive ways. First, the disproportionate impact of COVID-19-as measured by higher probabilities of contracting COVID-19 as well as dying from complications among Black, Indigenous and other people of color (BIPOC)highlights how White supremacy shapes the pre-existing structural inequalities that render BIPOC more vulnerable during the pandemic (Garcia et al. 2020; Pirtle 2020). Second, 
the resurgence and spread of the Black Lives Matter movement and social protests after the murder of George Floyd by police (and most recently the guilty verdict of police officer Derek Chauvin) despite the ongoing global pandemic demonstrate the critical need to eradicate the pervasive anti-Black racism (Kampmark 2020). Systemic racism is a public health threat analogous to the pandemic (O'Reilly 2020), and anti-Black racism, through multiple interconnected mechanisms, maintains White supremacy (Bonilla-Silva 2001). Lastly, the rise of anti-Asian and xenophobic rhetoric as well as hate incidents toward Asian Americans during the pandemic raise important questions about how White supremacy draws on racist nativism to maintain its status quo (Ho 2020).

The COVID-19 pandemic has made visible the mechanisms and pervasiveness of White supremacy in the United States, raising critical questions about how immigrants engage in the dialogue on White supremacy and systemic racism. We define White supremacy as a multipronged phenomenon that sustains White privilege through socioeconomic, legal, cultural, and materialist means. White supremacy maintains and accrues racial capital for White people through legal rights (e.g., naturalization, citizenship, and immigration) and economic gains (e.g., loans, housing, education, and promotions) that become culturally normalized as natural (Lipsitz 1995). In this way, White supremacy is omnipresent and, importantly, can be deployed in a number of ways, including by non-White people, both consciously and inadvertently (Smith 2012; Leong 2013). An understanding of the ways White supremacy is deeply embedded in U.S. culture and institutions and yet fluid as a system that can be supported and maintained by non-White people is particularly salient in this paper's definitions of "indifference" of Asian Americans toward Black Lives Matter (BLM). It is also important for highlighting the omnipresent nature of White supremacy and its multiply interconnected mechanisms to maintain its status quo. These issues are fundamental for realizing the linked fate of racialized and minoritized peoples working toward racial harmony and social justice (McGary 1997; West 1993).

As eloquently stated in the call for papers for this special issue, immigrants are often the victims of racial discrimination and racist nativism that leads to their marginalization in multiple ways. This is especially true for Asian immigrants and Asian Americans who, despite being marginalized, have also been accused of "not supporting mass movements for racial equality" and "trafficking in anti-Black racism". As the fastest -growing racial group with its population growth driven by immigration, how do Asian Americans fit into the dialogue on White supremacy and systemic racism? As a pan-ethnic group that is comprised of predominantly foreign-born members (66\% of all Asian Americans were foreign-born in 2018) (U.S. Census Bureau 2020), Asian Americans are uniquely situated to advance this inquiry and dialogue on the interconnections between immigration, White supremacy, and systemic racism. Prior research has documented the impact of racial discrimination and racist nativism on immigrants and the ensuing marginalization of Asian Americans (e.g., Chin 2020; Kuo 1995). Yet less is known about the degree to which Asian Americans' support for mass movements for racial equality and/or their perpetuation of anti-Black racism - especially in the context of the BLM movement-intervenes in Asian Americans' perceptions and feelings of their marginalization in the United States.

A critical assessment of Asian Americans' support of, opposition, and/or indifference to the BLM movement has important implications for studies of racial relations and solidarity, and for an understanding of the complex racial dynamics affecting Asian American communities. In a time of COVID-19, with heightened anti-Asian racism and xenophobia, Asian Americans are forced to acknowledge that several privileges (e.g., native-born status, U.S. citizenship, high educational attainment, professional jobs) do not offer "shields against xenophobia, racism, and scapegoating" (Lee 2020). With the complicit and active role Thou Thao played in the police murder of George Floyd and the election of Kamala Harris-the first Black-South Asian American Vice President, this moment provides opportunities for Asian Americans to reflect on difficult questions about anti-Black racism within Asian American communities. This reflection is critical for Asian Americans as they work toward realignment for racial harmony and social justice. The current paper explores how 
immigration plays a role in Asian Americans' indifference to supporting the BLM movement using the 2016 Collaborative Multiracial Post-Election Survey (CMPS), one of the first nationally representative surveys that contain information about the BLM movement. Specifically, drawing on theories of White supremacy, racial hierarchy in the United States, racial identities, and belonging, we investigate the individual-level predictors of reporting indifference to the BLM movement by nativity status among Asian Americans.

We focus on Asian Americans' indifference to the BLM movement rather than either support (e.g., cooperation) or opposition (e.g., conflict) to the BLM movement as the main outcome of interest for several reasons. For one, Asian Americans are more likely to support the BLM movement and less likely to oppose the BLM movement compared to non-Hispanic/Latinx White individuals (Horowitz and Livingston 2016; Parker et al. 2020; Thomas and Horowitz 2020). What is often missing from the dialogue about Asian Americans' participation in the BLM movement is the large proportion of those who report indifference to the BLM movement. While in survey research indifference is assumed value-neutral, we conceptualize indifference as a social relation rooted in urban social theory where indifference is "an ethical relation between subjects" (Tonkiss 2003, p. 298). That is, indifference is not value-neutral or an absence of opinion; rather, it is an intentional choice in a social relation to claim a solitude that can provide certain protections and freedoms afforded by privileges (Simmel [1903] 1997; Tonkiss 2003; Young 2011). Similarly, we argue that such silence-operationalized as indifference to the BLM movement-is a form of anti-Black racism and which can even lead to violence through complicity to White supremacist ideologies, regardless of intentions. Simply put, it is not merely enough for Asian Americans to "not be racist" but one must be "anti-racist" in the system of racial capitalism (Cheng 2013; Kendi 2019).

\section{The Stressful Commute}

\subsection{Racial Formation, Immigration and Complex Racial Positioning of Asian Americans}

"Asian American" as the pan-ethnic, political identity emerged in the 1960s when Chinese, Filipino, and Japanese American activists worked together for pan-Asian collective action to fight for their shared experience of racial discrimination and its struggles (Espiritu 1993; Okamoto 2003, 2014). The development of Asian American pan-ethnicity achieved through racialization and racial formation (Espiritu 1993; Okamoto 2003, 2014; Omi and Winant 1994) significantly contributed to mass movements for racial equality during the civil rights era (Espiritu 1993; Zia 2000). However, such an achievement was a double-edged sword. Many Americans began to accept the misconstrued notion of Asian American as a monolithic racial category, which in turn legitimized the misconception of the homogeneity of Asian Americans (Hollinger 2000). While pan-ethnicity helped to mobilize Asian American movements, the depiction of Asian Americans as the model minority erased the diversity of and differences within Asian America (e.g., not just ethnicity and culture but also of politics, history, class, gender, and sexuality) (Wu 2013). This singularity of Asian Americans as the model minority re-imagined them as the success story of American exceptionalism and meritocracy and viewed the as achieving socioeconomic success because of their hard work ethic and strong family values; it also ignored the hyper-selectivity of Asian immigrants based on post-1965 immigrant policies that targeted highly educated and professional immigrants (Zhou and Lee 2017). This re-imagined racial stereotype of Asian Americans as the model minority draws on a White supremacist logic that juxtaposes Asian Americans against Black Americans, obfuscating the role of systemic racism in the social injustices experienced by Black Americans (Matsuda 1993).

Since the 1960s, Asian Americans have experienced and led incredible demographic changes in the United States. Asian Americans were the only racialized group that was institutionally banned from immigration based on race by a series of nativist exclusionary immigration policies until the removal of the racial quota in 1965 (Lee 2015). It is important to keep in mind that the passing of the 1965 Immigration and Nationality Act was one of the legislations that came out of the civil rights movement to rectify past and 
ongoing racial discrimination. In many ways, Asian Americans owe their civil rights to the struggles for racial justice that Black Americans fought for. Before the passage of the 1965 act, Asian Americans comprised less than one million individuals to make up about $0.5 \%$ of the total U.S. population in 1960 (0.1\% Chinese Americans, $0.1 \%$ of Filipino Americans, and 0.3\% Japanese Americans) (U.S. Census Bureau 1960). Since then, the Asian American population has grown to 21 million individuals (6.4\% of the total U.S. population in 2018) (U.S. Census Bureau 2020) and Asian Americans now include diverse groups of people from more than two dozen countries with unique immigration histories, cultures, languages, modes of entry, and policy contexts. As of 2018 , about $66.3 \%$ of all Asian Americans were foreign-born compared to about $33.9 \%$ of all Hispanic/Latinx adults who were foreign-born (U.S. Census Bureau 2020). Furthermore, Asian Americans are the only group in which immigration is the key driver of its population growth. Such dynamic population composition changes and the increasing diversity within Asian America bring substantial complexities to a pan-ethnic identity formation (Okamoto 2003, 2014).

Increasingly becoming more heterogeneous, characteristics of lived experiences and identities of Asian Americans contribute to a complex racial positioning of Asian Americans, one that embraces both privilege and marginalization. Asian American positionality in the United States also challenges the theories of racial stratification that traditionally focuses on a Black-White binary where Black people are at the bottom and White people are on the top of the racial hierarchy; this largely ignores the nuances of racism that other racialized and minoritized people experience (Kao 2006; Perea 1998). To include increasing numbers of Asian Americans and Hispanics/Latinx, race scholars proposed a White/non-White divide (Skrentny 2001) and a Black/non-Black divide (López 1997; Yancey 2003). Yet both binary approaches fail to capture the heterogeneous experiences of racialized and minoritized populations (Kim 2007). The new conceptualization of a tri-racial stratification system advances this theorization by placing Asian Americans in between White and Black people with three categorizations: "whites", "honorary whites" (e.g., East Asian Americans), and "collective blacks" (e.g., darker-skinned and disadvantaged Southeast Asian Americans) (Bonilla-Silva 2004). While the new conceptualization pushed the discourse on racial relations beyond the binary paradigm, scholars argued that it still inadequately explains the racialization of Asian Americans (Gold 2004; Kim 1999). On the other hand, the racial triangulation theory expands the previous Black-White binary theory of racial stratification by arguing that the racial positions of Asian Americans differ from Black and White people at the intersection of "racial valorization" (i.e., racial hierarchy) and "civic ostracism" (i.e., insider/foreigner) dimensions (Kim 1999). This is an important theoretical expansion to illustrate how White supremacy simultaneously uses racial valorization to exploit Asian Americans to discount the role of systemic racism in the racial subordination of Black people while ostracizing Asian Americans as outsiders ( $\mathrm{Xu}$ and Lee 2013).

\subsection{Asian American Social Identity, Collective Action, and Intersectionality}

The complex racial positioning of Asian Americans has implications for whether, how, and in what contexts Asian Americans mobilize and participate in political processes-both individually and collectively. Theoretical perspectives on why individuals participate in collective action acknowledge that structural social factors, such as pan-ethnic identity formation and a complex racial positioning of Asian Americans, interplay with an individual's subjective conditions to influence their participation in collective action through interconnected mechanisms (Van Zomeren et al. 2008). In particular, the integrative Social Identity Model of Collective Action (SIMCA) theory presupposes that social identity is central to collective action (Van Zomeren et al. 2008) as social identity motivates individuals to mobilize for social change. The importance of social identity for collective action is based on the assumption that when members of a lower status group perceive their group-based relative deprivation they are more likely to identify with their group and engage in collective action for change. 
This is especially true for a politicized identity (Simon and Klandermans 2001). In this sense, a complex racial positioning of Asian Americans is critical as it can inform a perceived group status based on membership in the Asian American pan-ethnic category. Within this framework, perceived injustice is a key mediator where an individual's social identity affects collective action through its impact on how they perceive injustice (Thomas et al. 2020; Van Zomeren et al. 2008).

When considering the role of social identity in collective action for interracial solidarity for racial harmony and social justice, there are two major complexities for Asian Americans. First, it is unclear how theories of social identity and collective action incorporates the multiple social identities individuals navigate at the intersections of race/ethnicity, Indigeneity, immigration/citizenship status, gender, sexuality, class, and disability, among others (Wiley and Bikmen 2012). Similar to the racial triangulation theory (Kim 1999), individuals' social locations are multidimensional based on multiple social identities. For example, Asian American queer women may rank "higher" on the axis of racial valorization compared to Black cisgender men, but lower on the axes of gender and sexuality. An individual's social location is not merely the total sum of disadvantaged positions on various axes but uniquely and multidimensionally positioned (Collins 1990; Crenshaw 1990). This theory, however, does not explain how individuals' complex combinations of privileges and disadvantages motivate their intention for collective action for mass movement for racial equality (Wiley and Bikmen 2012). Second, as related to the importance of intersectionality, the experiences and perceptions of injustice differ by nativity status within Asian Americans, but how they are linked to collective action is unclear. Investigating the structural and psychological barriers for foreign-born Asian Americans' informal political participation, such as protest and community civic engagement, which appears less constrained by citizenship and legal limitations, have critical implications for the meaningful political incorporation of Asian immigrants (Ebert and Okamoto 2015; Lee and Kye 2016; Wong et al. 2011).

\subsection{Moving Beyond Race: Immigration, Black-Asian Solidarity and Black Lives Matter}

Although the model minority myth of Asian Americans often portrays Asian Americans as passive and inactive in political participation, Asian Americans have a rich history of activism and collective action-both within our own communities and with other marginalized communities (Espiritu 1993). Asian Americans have complicated histories of Black-Asian racial solidarities as well as Black-Asian racial conflicts. Asian Americans' active participation in the mass movement for racial equality during the civil rights movement is often remembered by well-known Asian American activists like Grace Lee Boggs and Yuri Kochiyama were part of the Black Power movement, and worked to build BlackAsian solidarity (Boggs 2016; Fujino 2005; Kochiyama 1994). Since the 1960s, substantial demographic and economic changes have offered opportunities for interracial solidarity through coalition building and cooperation between different racialized and minoritized groups (Kim and Lee 2001); yet they also came with new challenges to Black-Asian race relations. Most notably, the L.A. uprising of 1992 have been used extensively to reflect on Asian Americans' racial positioning, the development of the pan-ethnic Asian American identity, and activism (Nopper 2006). The prevalent narrative is that Korean immigrants whose stores were damaged during the uprising were innocent collateral damage who simply got caught between Black-White racial conflicts and later were abandoned by the state as the model minority (Abelmann and Lie 1997; Chang 2004). As elaborated elsewhere (Nopper 2006), this narrative is highly problematic as it erases the actual involvement of Korean Americans in racial conflicts "before, during, and after the riots" (Nopper 2006, p. 103). There is also an erasure of Korean American cooperation with Black communities (and Latinx communities) in these neighborhoods where they invested in local organizations and churches because that narrative does not serve White supremacist logics of racial conflict between minorities (Abelmann and Lie 1997; Kim 1993). More importantly, such framing led to the missed opportunities for critical inquiry on immigration, White supremacy, and systemic racism. 
Asian Americans' participation in the BLM movement is another opportunity for such a critical inquiry, especially to examine the role of immigration in collective action as Asian Americans are now comprised of predominantly foreign-born members. The BLM movement is a political and social movement first created by Alicia Garza, Patrisse KhanCullors, and Opal Tometi in response to the acquittal of 17-year-old Trayvon Martin's killer in July 2013 (Khan-Cullors 2018). Since 2013, it gained momentum and national recognition after the protests in 2014 following the police murders of Michael Brown in Ferguson, Missouri, and Eric Garner in New York City. Similar to other social movements, the BLM movement has had its own ebbs and flows (Della Porta 2013), but BLM protests after the police murder of George Floyd in May 2020 made BLM the largest social movement in U.S. history (Buchanan et al. 2020). BLM is not only a social movement to advocate for Black liberation but is a movement for anti-racist revolution. Although BLM acknowledges and honors the influences from the civil rights movement, one of the ways the BLM movement differentiates itself from prior movements is the consideration of intersectionality and community control to reject patriarchal and hetero-normative ideologies from prior movements (Clark et al. 2018). By paying attention to intersecting systems of privilege and oppression at the nexus of race, gender, sexualities, citizenship status, and disability, among others, BLM centers intersectional frameworks as the tool for social empowerment, reconstruction, and alliance-building against anti-Blackness (Crenshaw et al. 2015; Khan-Cullors 2018). In this way, BLM contributes to interracial solidarity by dismantling anti-Black racism and also underscores how interlocked forms of oppressions exist within and between our communities (Davis 2016; Maeda 2009; Takaki 1993).

According to the nationally representative surveys, Asian Americans were more likely to support the BLM movement and less likely to oppose the BLM movement compared to non-Hispanic/Latinx White individuals in 2016 and 2020 (Horowitz and Livingston 2016; Parker et al. 2020; Thomas and Horowitz 2020) (Figure 1). Yet given the diversity of Asian Americans, their relationship with the BLM movement is complex. In November 2014, in response to Peter Liang's police murder of an unarmed Black man, Akai Gurley, Asian Americans' positions substantially varied (Liu 2018; Tran et al. 2018). One group of Asian Americans formed the pro-Liang coalition as they felt that Liang was merely being scapegoated by White supremacy to attenuate the national attention from White-Black racial conflict (e.g., the police murder of Eric Garner that preceded Gurley's death). Another group of Asian Americans joined in solidary with Black communities and actively participated in the BLM movement (Liu 2018). The pro-Liang group used racial victimology and anti-Blackness as discursive strategies to center racism against Chinese Americans rather than acknowledging and fighting against the systemic racism in state-sanctioned violence against Black people (Liu 2018). Similar to Asian American assimilationist politics, another discursive strategy used by the pro-Liang group was the American Dream discourse where Liang's "unfair" indictment was framed as the hindrance for the model minority (Liu 2018). It is important to note that there has been a persistent presence of Asian American activists supporting the BLM movement (Liu 2018) and community collaborations for Black-Asian solidarity (e.g., Hope 2019). Yet, in the function and logic of White supremacy, the erasure of Asian American mobilization and care work pits Black Americans and Asian Americans consistently at odds with each other, where one group is seen as taking rights and privileges away from the other minoritized group. 


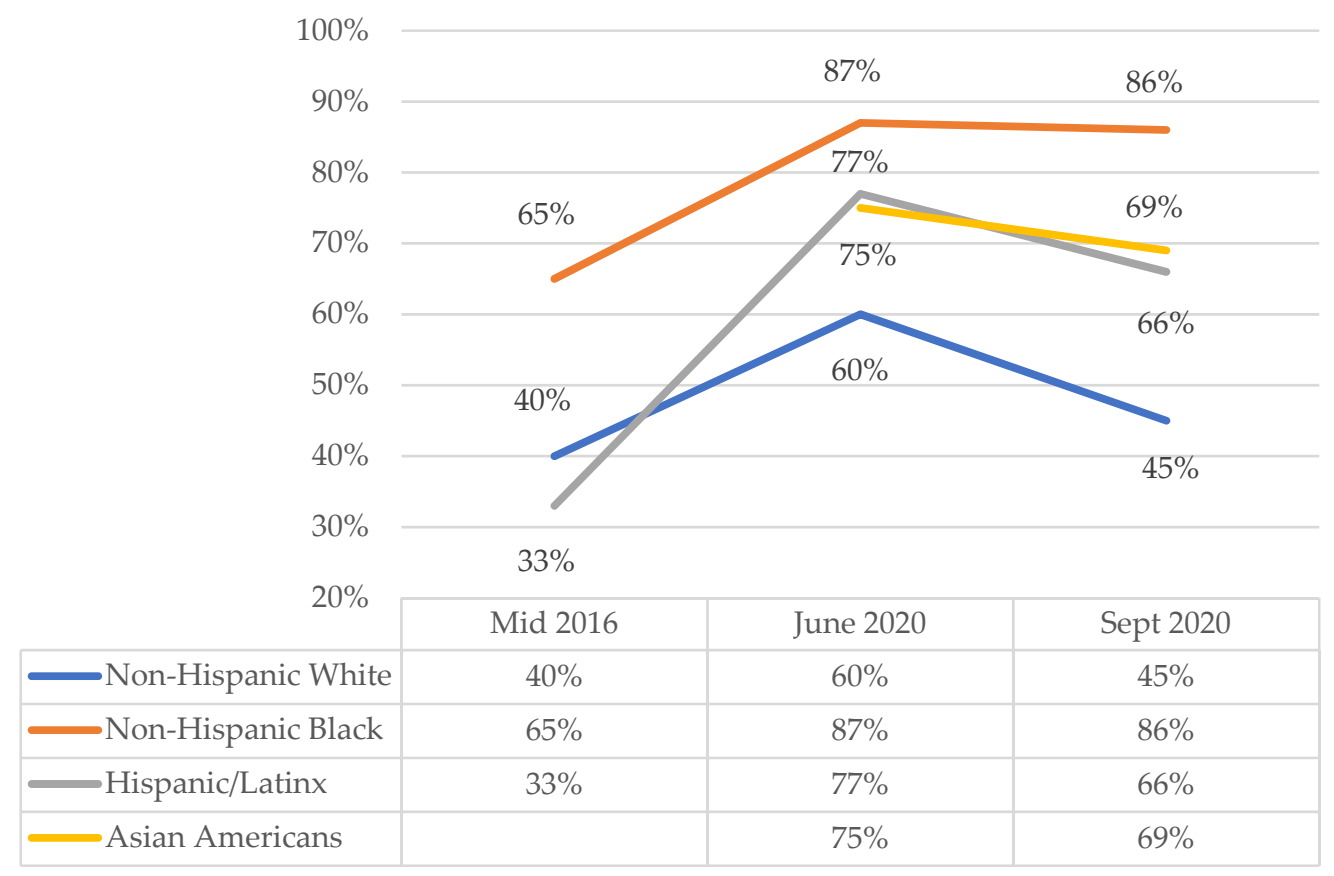

Figure 1. Changes in percentages of supporting Black Lives Mater by racialized groups for non-Hispanic/Latinx White, non-Hispanic/Latinx Black, Hispanic/Latinx, and Asian American adults 2016-2020. Source: Three nationally representative surveys conducted by Pew Research Center. Note: Estimates for 2016 come from Horowitz and Livingston (2016); June 2020 estimates come from Parker et al. (2020); and Sept 2020 estimates come from Thomas and Horowitz (2020). Asian Americans were not included in the survey in 2016.

\subsection{Immigration and the Ethics of Political Indifference: "Yellow Fragility" and/or Belonging}

Asian Americans' political participations in both formal and informal activities are important aspects of political incorporation and representation (Lee and Kye 2016). Although socioeconomic status indicators (e.g., high level of income, education, etc.) are strong predictors of political participation in general (Milbrath and Goel 1977), Asian Americans' political participation is substantially lower than other racialized and minoritized groups (Lien et al. 2004). This is partially explained by the findings that foreign-born status and other immigration-related factors (e.g., English proficiency) are key predictors for the low level of Asian American political participation (Lien et al. 2004; Ramakrishnan and Espenshade 2001; Wong et al. 2011; Xu 2005). However, these status indicators do not necessarily explain the low political participation of third-generation Asian Americans who are still significantly less likely to participate in political activities compared to other racialized and minoritized groups (Lien et al. 2004; Ramakrishnan and Espenshade 2001). Lower political participation and the "fantasy of politically neutral" (Liu 2018, p. 445) pose critical challenges for Asian Americans' efforts toward building interracial solidary for racial harmony and social justice. For example, although indifference to the BLM movement is often conceptualized to reflect political neutrality or inaction, we offer that such indifference is a specific kind of active dissociation that reproduces anti-Black violence and complicity with White supremacy regardless of intentions (Kendi 2019; Liu 2018). For Asian Americans to work toward interracial solidary for racial harmony and social justice, the first step is to critically interrogate the anti-Black racism within Asian American communities, which is at times read as indifference to the BLM movement.

In addition to structural barriers for Asian immigrants' political participation, the common explanation for Asian Americans' political indifference relies on the inadequate assumption of immigrant innocence within the assimilationist framework. The assumption is that Asian immigrants do not understand anti-Black racism upon arrival and that their understanding of racism and racial consciousness will grow with more time in the United States (Liu 2018). This is partially supported by key empirical findings that experiences 
of one's own discrimination is a strong predictor for political participation among Asian immigrants (Ramakrishnan and Espenshade 2001; Wong et al. 2011). While Asian immigrants may have less understanding of racial relations in the localized U.S. context than their U.S.-born counterparts, it is problematic and paternalistic to assume that Asian immigrants do not have racial consciousness until their arrival as it overlooks transnational and historical racial formations and anti-Black racism in Asia (Kim 2015; Kim and Jung 2019; Kwon 2017). Rather, it is important to interrogate if Asian Americans' political indifference is another form of "performance of whiteness" deriving from internalizing racism as an adaptive strategy to survive White supremacy (Liu 2018, p. 435; Tran et al. 2018). That is, Asian Americans' political indifference can simultaneously come from less knowledge on the complexities of racial relations in the United States and/or from the willful ignorance of embracing colorblind ideologies. Similar to White fragility-the discomfort with racial stress that motivates White individuals to take defensive actions (DiAngelo 2018)-Asian Americans may use inaction to create solitude from their discomfort with racial stress from White people and other people of color.

Another critical yet often overlooked dimension to consider is the role of Asian Americans' sense of belonging in political indifference. Belonging refers to "a sense of ease with oneself and one's surrounding" (May 2011, p. 368). The concept of belonging is often intertwined with and used synonymously with identity and citizenship; yet belonging is a multidimensional concept that is distinct from identity and citizenship (Antonsich 2010). As an analytic framework, belonging consists of two interrelated dimensions where the first dimension of place-belongingness (e.g., an emotional connection in a place) is associated with a sense of ownership (e.g., of a place) that leads to the politics of belonging (Antonsich 2010; Crowley 1999). Sociologists observed that belonging is central to connecting individuals to social change (May 2011), and this is achieved by how one knows the social rules of engagement (e.g., the existence of a shared culture) and perceives the right to participate in the development of social rules (e.g., perceived decision-making power) (Bottero 2010; Fortier 2000). Analogous to the ways Asian Americans' colorblind ideologies stem out of internalized racism, lacking a sense of belonging may be the internalized form of racist nativism where Asian Americans may feel alienated from the decision-making process in the United States as they are systematically marginalized in the United States because of White supremacy (Hong 2020).

\section{The Current Study}

In summary, the current study examined individual-level predictors of reporting indifference to the BLM movement by nativity status among Asian Americans. This study contributes to the critical question about how immigrants fit into the dialogue on White supremacy and systemic racism. Our analysis aimed to address the research question: What contributes to Asian American's reported indifference to the BLM movement? Specifically, we tested three interrelated hypotheses. The first hypothesis was that Asian Americans' collective odds of reporting indifference to the BLM movement differed based on nativity. Similar to how other forms of political participation of Asian Americans vary by nativity (Ramakrishnan and Espenshade 2001; Wong et al. 2011), we expected to find that foreignborn Asian Americans were more likely to report indifference to the BLM movement compared to their U.S.-born counterparts (i.e., lower participation in mass mobilization for racial equality). The second hypothesis was that higher levels of belonging would be associated with lower collective odds of reporting indifference to the BLM movement among Asian Americans, regardless of nativity. This expectation was informed by previous research on how emotional connection to a place was associated with a sense of ownership that led to greater politics of belonging (Antonsich 2010; Crowley 1999). We hypothesized that Asian Americans who report a stronger sense of belonging to the United States would be less likely to report indifference to the BLM movement. Our third hypothesis was that Asian Americans', regardless of nativity, knowledge and explicit acknowledgement of racism in the United States was associated with lower collective odds of reporting 
indifference to the BLM movement. Instead of taking defensive actions and embracing colorblind ideologies from racial stress (DiAngelo 2018), we hypothesized that Asian Americans who explicitly acknowledge that there is a lot of racial discrimination against Black Americans would be less likely to report indifference to the BLM movement.

\section{Materials \& Methods}

\subsection{Data}

We used the 2016 Collaborative Multiracial Post-Election Survey (CMPS), one of the few nationally representative surveys that include detailed information about support of the Black Lives Matter movement (Barreto et al. 2017). The CMPS also collected rich information about individuals' attitudes and perceptions about the 2016 United States election, immigration, racial justice, and racial discrimination experiences among Black American, Latinx, Asian American, and non-Hispanic/Latinx White adults (Barreto et al. 2017; Barreto et al. 2018). The CMPS utilized listed and density-sampling sources coupled with stratification on specific demographic characteristics to ensure representative samples (Barreto et al. 2018) and the survey was available in multiple languages, including English, Spanish, Chinese, Vietnamese, and Korean (Barreto et al. 2018). A total of 10,145 adults completed the online survey from December 2016 to February 2017 for a response rate of 9.9\%. The survey included 1045 White people; 3102 Black Americans; 3002 Latinx; and 3006 Asian Americans (Barreto et al. 2018). The CMPS has unique strengths to investigate within-group differences within the pan-ethnic category of Asian Americans as it included robust sample sizes of Asian ethnic groups. Detailed information about the complex survey design is available elsewhere (see Barreto et al. 2018). We restricted our analytic sample to individuals who self-identified as Asian $(n=3006)$, consisting of 1371 Asian immigrants (i.e., foreign-born Asian Americans) and 1635 U.S.-born Asian Americans. Our analytic sample includes 957 Chinese (reference), 118 Taiwanese, 483 Indian, 211 Korean, 410 Filipinx, 205 Vietnamese, 363 Japanese, and 259 Other Asian Americans.

\subsection{Measures}

The dependent variable, indifference to the BLM movement, is a dichotomous variable. It came from the question where the respondents were asked, "From what have you heard about the Black Lives Matter movement; do you support the Black Lives Matter movement activism?" Participant responses were recorded on a five-point Likert scale with responses including 0 (strongly oppose), 1 (somewhat oppose), 2 (neither support nor oppose), 3 (somewhat support), and 4 (strongly support). If individuals reported that they "neither support nor oppose" the movement, they were coded 1 (e.g., coded 0 for others).

Our three focus variables were: nativity, belonging, and acknowledgement of antiBlack racism. Nativity (foreign born) was a dichotomous variable where the respondents were coded as 1 if born outside of the United States (e.g., 0 if born in the United States). Belonging was calculated on a scale of 0 to 3 based on the answer to the question, "How strongly do you feel like you belong in the United States?" Respondent responses were recorded on a five-point Likert scale with responses including 0 (not at all belong), 1 (slightly belong), 2 (moderately belong), and 3 (strongly belong). Higher scores indicated a higher sense of belonging. Acknowledgement of anti-Black racism was a dichotomous variable based on the question, "How much discrimination is there in the United States today against Blacks?" If the respondent indicated "A lot", then they were coded as 1 (0 if they indicated "some", "a little", "none at all" or "don't know"). The variable was intended to conceptually capture the knowledge of anti-Black racism in the United States as well as the explicit acknowledgement of anti-Black racism.

There were six complementary key variables in addition to three focus variables. Following Antonsich (2010) we conceptualized belonging as a separate construct from identity and citizenship, which is often used synonymously, by including additional variables for identities and citizenship. We included three scale variables (ranging from 0 to 10) for three identity variables: American identity, Asian American identity, and ethnic identity 
(e.g., Korean). These variables were calculated based on the question, "Please indicate to what extent you think of yourself as each of the following identity" where 0 indicated "not at all" to 10 indicated "quite a lot". Citizenship status was a dichotomous variable where respondents were coded 1 if they were born in the United States or naturalized citizens. In addition to the indicator of acknowledgement of anti-Black racism, we included two additional variables that may be linked to individuals' perception and understanding of race and racism. One's own racial discrimination experience was coded as 1 if individuals reported having been discriminated against based on their racial background or ethnicity. The intergroup contact theory posits that contact between groups can change the racial ideas and prejudice, for better or for worse (Allport 1954; Pettigrew 1998); we included the percentage of Black residents in one's neighborhood as a proxy for contact.

We included several sociodemographic characteristics as control variables. Ethnicity was operationalized as a set of eight dichotomous variables to indicate the self-identified ethnicity: Chinese (reference), Taiwanese, Indian, Korean, Filipinx, Vietnamese, Japanese, and Other Asian Americans. Female was coded 1 if indicated female. Although the Other category was offered for the question asking for gender, there were only 7 Asian American respondents who selected the category. The use of female was not intended to dichotomize gender and marginalize individuals who identify as non-binary and genderqueer, but due to limitations of the data. LGBTQ+ sexual orientation was a dichotomous variable where respondents who self-identified as Gay, Lesbian, Bisexual, Transgender, Queer or Other were coded 1 ( 0 if indicated heterosexuality). Consistent with the Pew Research Center's operationalizations of generations (Dimock 2019), we included a set of five dichotomous variables to reflect the distinct generations. The Greatest Generation included individuals born prior to 1946 (e.g., 73 years and older at the time of the survey), Baby Boomers were individuals born between 1946 and 1964 (e.g., 52 to 72 years), Generation X included individuals born between 1965 and 1980 (e.g., 36 to 51 years), Millennials were individuals born between 1981 and 1996 (e.g., 35 to 20 years), and Generation Z were individuals born after 1997 (e.g., 18 and 19 years). Generation $Z$ was the reference group. Marital status was coded 1 if married. Skin color was a scale variable ranging from 1 to 10 based on the question where the respondents were asked to identify the hand that "comes closest to your skin color" from the 10 shades of skin color.

We also included four economic and political characteristics as control variables. We included two dichotomous variables for college and beyond education and full-time employment. A set of four dichotomous variables were included for household income: less than $\$ 40,000 ; \$ 40,000$ to $\$ 69,999 ; \$ 70,000$ to $\$ 99,999$; and $\$ 100,000$ and more (reference). Conservative political ideology was coded 1 if identified as conservative and coded 0 if identified as moderate or liberal political ideologies.

\subsection{Analytic Approach}

There were four variables with less than $1.0 \%$ missing data (i.e., citizenship, age, female, skin color) and about $11.9 \%$ of information about household income $(n=357)$ was missing. We used the multivariate regression multiple imputation methods to account for missing values to generate the correct parameter estimates and standard errors by creating 25 imputed data sets following the recommendations for the best practices in analyzing survey data with missing values (Johnson and Young 2011). We conducted ancillary analysis using the listwise deletion, and all results were substantively and significantly similar. To account for the complex survey sampling design and generation of the nationally representative estimates (based on 2015 American Community Survey estimates), we used the appropriate survey weight (Barreto et al. 2018). We ran a set of logistic regression models. Finally, we checked for variance inflation factors (VIF) to avoid multicollinearity. 


\section{Results}

\subsection{Descriptive Statistics}

Prior to presenting the descriptive statistics of the analytic sample of Asian Americans for the study, we provide the distributions of three key variables (i.e., supporting BLM, belonging, and acknowledgement of anti-Black racism) across multiple racialized groups first in Table 1. A higher percentage of Asian Americans supported the BLM movement (40.2\%) compared to non-Hispanic/Latinx White adults (26.7\%), but this was much lower than the percentage of non-Hispanic/Latinx Black adults for supporting the BLM movement $(70.1 \%)$. Similarly, the percentage of Asian Americans opposing the BLM movement (17.4\%) was significantly lower compared to non-Hispanic/Latinx White adults (44.4\%) but higher compared to non-Hispanic/Latinx Black adults (7.5\%). The differences existed in the percentages of each group reporting indifference to the BLM movement where Asian Americans had the highest percentage (42.5\%) compared to non-Hispanic/Latinx White (28.9\%), non-Hispanic/Latinx Black (22.4\%), and Hispanic/Latinx (37.1\%) adults. Asian Americans also had the lowest level of belonging compared to any other groups. Compared to non-Hispanic/Latinx Black and Hispanic/Latinx adults, a lower percentage of Asian Americans reported acknowledging that there is a lot of Black discrimination in the United States, but a higher percentage of Asian Americans explicitly acknowledged that there is a lot of Black discrimination compared to non-Hispanic White adults (32.7\% of Asian Americans vs. $26.6 \%$ of non-Hispanic/Latinx White adults).

Table 1. Distributions of supporting BLM, belonging, and acknowledgement of anti-Black racism across racialized groups. Source: 2016 Collaborative Multiracial Post-election Survey (CMPS). Note: Statistics are weighted to produce the nationally representative estimates to 2015 U.S. population. Estimates are based on 10,144 individuals including 1034 Non-Hispanic White; 3102 Non-Hispanic Black; 3002 Hispanic/Latinx; and 3006 Asian American adults in 2016 CMPS.

\begin{tabular}{|c|c|c|c|c|c|}
\hline & $\%$ Support of BLM & $\%$ Indifferent of BLM & $\%$ Oppose of BLM & Belonging & $\begin{array}{l}\% \text { Acknowledgement } \\
\text { of Anti-Black Racisms }\end{array}$ \\
\hline Non-Hispanic White & $26.7 \%$ & $28.9 \%$ & $44.4 \%$ & 2.69 & $26.6 \%$ \\
\hline Non-Hispanic Black & $70.1 \%$ & $22.4 \%$ & $7.5 \%$ & 2.45 & $69.1 \%$ \\
\hline Hispanic/Latinx & $45.3 \%$ & $37.1 \%$ & $17.6 \%$ & 2.44 & $48.7 \%$ \\
\hline Asian Americans & $40.2 \%$ & $42.5 \%$ & $17.4 \%$ & 2.27 & $32.7 \%$ \\
\hline Foreign-born Asian Americans & $42.0 \%$ & $40.0 \%$ & $18.0 \%$ & 2.47 & $45.2 \%$ \\
\hline U.S.-born Asian Americans & $39.1 \%$ & $43.3 \%$ & $17.6 \%$ & 2.21 & $28.8 \%$ \\
\hline Total & $35.5 \%$ & $30.1 \%$ & $34.4 \%$ & 2.60 & $35.6 \%$ \\
\hline
\end{tabular}

Table 2 presents weighted descriptive statistics of the key variables for Asian Americans by total amount and by nativity. Compared to the national estimate $(66.3 \%)$, lower percentages of Asian Americans in our analysis (45.6\%) were foreign born; about $56 \%$ of the foreign-born Asian Americans were naturalized citizens. The percentage of Asian Americans reporting indifference to the BLM movement significantly varied by nativity status where a higher percentage of foreign-born Asian Americans (43.3\%) reported indifference to BLM movement compared to their U.S.-born counterparts (40.0\%). Foreign-born Asian Americans reported significantly lower belonging compared to U.S.-born Asian Americans (2.21 vs. 2.47); significantly fewer foreign-born Asian Americans acknowledged that there is a lot of Black discrimination in the United States (28.8\% compared to $45.2 \%$ of U.S.-born Asian Americans). Unsurprisingly, U.S.-born Asian Americans put significantly higher importance on their American identity and Asian American identity whereas foreignborn Asian Americans put significantly higher importance on their ethnic identity. Lastly, a significantly higher percentage of U.S.-born Asian Americans reported having experienced racial discrimination (45.2\%) compared to foreign-born Asian Americans (37.4\%).There were other group differences by nativity in sociodemographic, economic, and political characteristics. Compared to U.S.-born Asian Americans, foreign-born Asian Americans were married at higher percentages and self-reported as having slightly darker skin color. A higher percentage of foreign-born Asian Americans had college and beyond educational attainment 
(57.5\% vs. $44.1 \%$ of U.S.-born Asian Americans). Although the group differences were not statistically significant, a higher percentage of U.S.-born Asian Americans were represented in the bottom household income category, making less than $\$ 40,000$ a year, and a higher percentage of foreign-born Asian Americans had a conservative political ideology.

Table 2. Weighted descriptive statistics of all variables for Asian Americans, by nativity. Source: 2016 Collaborative Multiracial Post-election Survey (CMPS). Note: Statistics a Significant tests of difference compared to U.S.-born Asian Americans, $p<0.05$ (one-tailed test); ${ }^{*} p<0.05,{ }^{* *} p<0.01,{ }^{* * *} p<0.001,+p<0.10$.

\begin{tabular}{|c|c|c|c|c|c|c|c|}
\hline & \multicolumn{2}{|c|}{ Total } & \multicolumn{2}{|c|}{$\begin{array}{l}\text { U.S. Born } \\
(n=1635)\end{array}$} & \multicolumn{2}{|c|}{$\begin{array}{l}\text { Foreign Born } \\
\quad(n=1371)\end{array}$} & \multirow[b]{2}{*}{ diff } \\
\hline & $\% / \mathrm{m}$ & std & $\% / \mathrm{m}$ & std & $\% / \mathrm{m}$ & std & \\
\hline Indifference to BLM & $42.5 \%$ & 0.49 & $40.0 \%$ & 0.49 & $43.3 \%$ & 0.50 & $* * *$ \\
\hline \multicolumn{8}{|l|}{ Key Variables of Interests } \\
\hline Foreign born & $45.6 \%$ & 0.43 & $0.0 \%$ & 0.00 & $100 \%$ & 0.00 & \\
\hline Belonging & 2.27 & 0.81 & 2.47 & 0.78 & 2.21 & 0.81 & $* * *$ \\
\hline American identity (0-10) & 7.02 & 2.95 & 8.19 & 2.42 & 6.66 & 3.00 & $* * *$ \\
\hline Asian American identity (0-10) & 7.33 & 2.70 & 8.07 & 2.58 & 7.10 & 2.70 & $* * *$ \\
\hline Ethnic identity $(0-10)$ & 7.33 & 2.87 & 7.08 & 2.96 & 7.41 & 2.84 & $* * *$ \\
\hline Citizenship status & $66.5 \%$ & 0.47 & $100 \%$ & 0.00 & $56.0 \%$ & 0.50 & $* * *$ \\
\hline Acknowledgement of anti-Black racisms & $32.7 \%$ & 0.47 & $45.2 \%$ & 0.50 & $28.8 \%$ & 0.45 & $* * *$ \\
\hline Own racial discrimination experience & $39.7 \%$ & 0.49 & $46.9 \%$ & 0.50 & $37.4 \%$ & 0.48 & $* * *$ \\
\hline$\%$ Black residents in neighborhood & $7.0 \%$ & 1.08 & $11.1 \%$ & 1.17 & $5.8 \%$ & 1.05 & \\
\hline \multicolumn{8}{|l|}{ Sociodemographic Characteristics } \\
\hline \multicolumn{8}{|l|}{ Ethnicity } \\
\hline Chinese & $21.5 \%$ & 0.41 & $28.4 \%$ & 0.45 & $19.4 \%$ & 0.40 & $* * *$ \\
\hline Taiwanese & $2.8 \%$ & 0.16 & $1.5 \%$ & 0.12 & $3.2 \%$ & 0.18 & $*$ \\
\hline Indian & $21.2 \%$ & 0.41 & $9.1 \%$ & 0.29 & $25.0 \%$ & 0.43 & $* * *$ \\
\hline Korean & $9.1 \%$ & 0.29 & $9.0 \%$ & 0.29 & $9.2 \%$ & 0.29 & * \\
\hline Filipinx & $17.2 \%$ & 0.38 & $13.7 \%$ & 0.34 & $18.3 \%$ & 0.39 & $* * *$ \\
\hline Vietnamese & $10.5 \%$ & 0.31 & $15.3 \%$ & 0.36 & $9.0 \%$ & 0.29 & $* * *$ \\
\hline Japanese & $5.1 \%$ & 0.22 & $11.6 \%$ & 0.32 & $3.1 \%$ & 0.17 & $* * *$ \\
\hline Other Asian Americans & $12.5 \%$ & 0.33 & $11.4 \%$ & 0.32 & $12.8 \%$ & 0.33 & \\
\hline Female & $50.9 \%$ & 0.50 & $50.5 \%$ & 0.50 & $51.0 \%$ & 0.50 & \\
\hline LGBTQ+ sexual orientation & $10.1 \%$ & 0.30 & $10.6 \%$ & 0.31 & $10.0 \%$ & 0.30 & \\
\hline \multicolumn{8}{|l|}{ Generation } \\
\hline Greatest Generation & $6.9 \%$ & 0.25 & $5.4 \%$ & 0.23 & $7.3 \%$ & 0.26 & \\
\hline Baby Boomer & $24.2 \%$ & 0.43 & $22.5 \%$ & 0.42 & $24.8 \%$ & 0.43 & \\
\hline Millennials & $28.2 \%$ & 0.45 & $23.5 \%$ & 0.42 & $29.7 \%$ & 0.46 & \\
\hline Generation X & $33.6 \%$ & 0.47 & $35.5 \%$ & 0.48 & $33.0 \%$ & 0.47 & $* *$ \\
\hline Generation Z (ref) & $7.1 \%$ & 0.26 & $13.1 \%$ & 0.34 & $5.2 \%$ & 0.22 & $* * *$ \\
\hline Marital status (Married) & $58.6 \%$ & 0.49 & $42.0 \%$ & 0.49 & $63.7 \%$ & 0.48 & $* * *$ \\
\hline Skin color & 3.44 & 1.34 & 3.38 & 1.35 & 3.46 & 1.34 & $*$ \\
\hline \multicolumn{8}{|l|}{ Economic and Political Characteristics } \\
\hline Education (College and beyond) & $54.3 \%$ & 0.50 & $44.1 \%$ & 0.50 & $57.5 \%$ & 0.49 & $* * *$ \\
\hline Employed (Full-time) & $41.1 \%$ & 0.49 & $41.7 \%$ & 0.49 & $40.9 \%$ & 0.49 & + \\
\hline \multicolumn{8}{|l|}{ Household income } \\
\hline Less than $\$ 40,000$ & $29.2 \%$ & 0.45 & $32.1 \%$ & 0.47 & $28.3 \%$ & 0.45 & \\
\hline$\$ 40,000$ to $\$ 69,999$ & $24.4 \%$ & 0.43 & $21.9 \%$ & 0.41 & $25.2 \%$ & 0.43 & * \\
\hline$\$ 70,000$ to $\$ 99,999$ & $20.0 \%$ & 0.40 & $19.3 \%$ & 0.40 & $20.2 \%$ & 0.40 & \\
\hline$\$ 100 \mathrm{k}$ more & $26.4 \%$ & 0.44 & $26.6 \%$ & 0.44 & $26.3 \%$ & 0.44 & * \\
\hline Conservative political ideology & $19.3 \%$ & 0.39 & $17.6 \%$ & 0.38 & $19.9 \%$ & 0.40 & \\
\hline
\end{tabular}

\subsection{Multivariate Results}

Table 3 presents the results from the logistic regression models in terms of odds of reporting indifference to the BLM movement. Model 1 starts by showing the nativity status difference in the collective odds for Asian Americans reporting indifference to the BLM movement. Model 2 adds information about belonging, identities, and citizenship status. Model 3 is the saturated model with added information about acknowledgement of anti-Black racism and one's own racial discrimination experience. After obtaining the final model (i.e., Model 3), we stratified the model by nativity to see whether and how individual characteristics might differently predict reporting indifference to the BLM movement. Model 3A is the stratified Model 3 for U.S.-born Asian Americans; Model 3B is the stratified Model 3 for foreign-born Asian Americans. 
Table 3. Weighted logistic regression predicting indifference in support BLM (odds ratios). Source: 2016 Collaborative Multiracial Post-election Survey (CMPS). Note: Statistics a Significant tests of difference compared to U.S.-born Asian Americans, $p<0.05$ (one-tailed test); ${ }^{*} p<0.05,{ }^{* *} p<0.01,{ }^{* * *} p<0.001,+p<0.10$.

\begin{tabular}{|c|c|c|c|c|c|c|c|c|c|c|}
\hline \multirow{2}{*}{ Key Variables of Interests } & \multicolumn{2}{|c|}{ Model 1} & \multicolumn{2}{|c|}{ Model 2} & \multicolumn{2}{|c|}{ Model 3} & \multicolumn{2}{|c|}{ Model 3A (USB) } & \multicolumn{2}{|c|}{ Model 3B (FB) } \\
\hline & & & & & & & & & & \\
\hline Foreign born & 1.19 & * & 1.09 & & 1.03 & & & & & \\
\hline Belonging & & & 0.89 & * & 0.89 & * & 0.87 & * & 0.94 & \\
\hline American Identity $(0-10)$ & & & 0.96 & $* * *$ & 0.97 & & 0.97 & & 0.97 & \\
\hline Asian American Identity (0-10) & & & 0.99 & & 1.01 & & 0.97 & & 1.01 & \\
\hline Ethnic Identity $(0-10)$ & & & 1.00 & & 1.01 & & 1.04 & + & 0.97 & \\
\hline Citizenship status & & & 1.02 & & 1.08 & & 1.00 & & 1.16 & \\
\hline \multicolumn{11}{|l|}{ Acknowledgement of anti-Black } \\
\hline racisms & & & & & 0.48 & $* * *$ & 0.48 & $* * *$ & 0.42 & $* * *$ \\
\hline Own racial discrimination experience & & & & & 0.74 & $* * *$ & 0.77 & * & 0.72 & ** \\
\hline$\%$ Black residents in neighborhood & & & & & 0.94 & + & 0.97 & & 0.94 & \\
\hline \multicolumn{11}{|l|}{ Sociodemographic Characteristics } \\
\hline \multicolumn{11}{|l|}{ Ethnicity (ref: Chinese) } \\
\hline Taiwanese & 1.07 & & 1.05 & & 1.23 & & 0.84 & & 1.73 & \\
\hline Indian & 0.96 & & 0.96 & & 0.92 & & 0.65 & * & 1.06 & \\
\hline Korean & 0.78 & + & 0.83 & & 1.07 & & 1.47 & + & 0.90 & \\
\hline Filipinx & 0.86 & & 0.88 & & 1.02 & & 0.99 & & 1.14 & \\
\hline Vietnamese & 1.25 & + & 1.31 & * & 1.26 & & 1.45 & + & 0.96 & \\
\hline Japanese & 0.87 & & 0.87 & & 0.99 & & 0.97 & & 1.16 & \\
\hline Other Asian Americans & 0.87 & & 0.88 & & 0.95 & & 1.19 & & 0.74 & \\
\hline Female & 1.13 & + & 1.13 & + & 1.18 & * & 1.13 & & 1.27 & + \\
\hline LGBTQ+ sexual orientation & 0.92 & & 0.88 & & 0.81 & & 0.74 & & 0.92 & \\
\hline \multicolumn{11}{|l|}{ Generation (ref: Gen Z) } \\
\hline Greatest Generation & 2.56 & $* * *$ & 2.74 & $* * *$ & 2.33 & ** & 3.00 & ** & 1.88 & \\
\hline Baby Boomer & 2.19 & $* * *$ & 2.34 & $* * *$ & 1.90 & ** & 2.15 & ** & 1.82 & \\
\hline Millennials & 2.21 & $* * *$ & 2.24 & $* * *$ & 1.87 & ** & 1.60 & + & 2.47 & * \\
\hline Generation X & 1.86 & $* *$ & 1.84 & $* *$ & 1.57 & * & 1.64 & $*$ & 1.65 & \\
\hline Marital status (Married) & 1.51 & $* * *$ & 1.48 & $* * *$ & 1.46 & $* * *$ & 1.46 & $* *$ & 1.64 & $* * *$ \\
\hline Skin color & & & 1.01 & & 1.00 & & 0.97 & & 1.05 & \\
\hline \multicolumn{11}{|l|}{ Economic and Political Characteristics } \\
\hline Education (College and beyond) & 0.81 & * & 0.80 & * & 0.82 & * & 0.66 & ** & 1.09 & \\
\hline Employed (Full-time) & 0.95 & & 0.96 & & 0.98 & & 1.00 & & 0.99 & \\
\hline \multicolumn{11}{|l|}{ Household income (ref: \$100k more) } \\
\hline Less than $\$ 40,000$ & 1.78 & $* * *$ & 1.70 & $* * *$ & 1.69 & $* * *$ & 1.31 & + & 2.22 & $* * *$ \\
\hline$\$ 40,000$ to $\$ 69,999$ & 1.49 & $* * *$ & 1.44 & ** & 1.39 & ** & 1.22 & & 1.63 & $* *$ \\
\hline$\$ 70,000$ to $\$ 99,999$ & 1.48 & $* * *$ & 1.44 & $* * *$ & 1.36 & ** & 1.18 & & 1.55 & $*$ \\
\hline Conservative political ideology & 0.74 & ** & 0.75 & $* *$ & 0.67 & $* * *$ & 0.54 & $* * *$ & 0.85 & \\
\hline Constant & 0.21 & $* * *$ & 0.41 & ** & 0.53 & * & 0.53 & & 0.29 & * \\
\hline
\end{tabular}

Model 1 results show that foreign-born Asian Americans were 19 percent more likely to report indifference to the BLM movement compared to their U.S.-born Asian American counterparts. Korean Americans were less likely to report indifference to the BLM movement and Vietnamese Americans were more likely to report indifference to the BLM movement compared to Chinese Americans, although both associations were marginally significant at $<0.10$. Once we controlled for belonging, identities, and citizenship, the nativity difference of subjects' indifference to the BLM movement was no longer significant. Individuals who reported greater belonging were less likely to report indifference to the BLM movement. The association was similar for American identity but the magnitude was smaller (about $4 \%$ reduction in odds compared to $11 \%$ reduction associated with belonging). Asian American identity, ethnic identity, and citizenship status were not significantly nor substantially associated with indifference to the BLM movement.

When we accounted for three variables on perception and understanding of race and racism (Model 3), the significant association between American identity and indifference to the BLM movement disappeared but the association between belonging and indifference to the BLM movement did not change. Acknowledgement of anti-Black racism reduced the odds of reporting indifference to the BLM movement by $52 \%$ and one's own racial discrimination experience reduced the odds of reporting indifference to the BLM movement by $26 \%$ controlling for various sociodemographic, economic, and political characteristics. 
Group differences in indifference to the BLM movement by ethnicity also disappeared once we included the control variables. Results from the stratified models by nativity status showed that the acknowledgement of anti-Black racism and one's own racial discrimination experience were both associated with significantly reduced odds of reporting indifference to the BLM movement for both foreign-born and U.S.-born Asian Americans. However, the association between belonging and indifference to the BLM movement was only significant for U.S.-born Asian Americans in which greater belonging was associated with lower odds of reporting indifference to the BLM movement.

Compared to Generation Z, older Asian Americans in other generational categories were more likely to report indifference to the BLM movement for only U.S.-born Asian Americans (except for the higher odds of reporting indifference to the BLM movement for foreign-born Asian American Millennials). Among U.S.-born Asian Americans, older generations were significantly and substantially more likely to report indifference to the BLM movement. For both groups, being married was associated with higher odds of reporting indifference to the BLM movement. Some significant associations of various sociodemographic, economic, and political characteristics with indifference to the BLM movement differed by nativity. Having college and beyond education levels and a conservative political ideology were associated with the reduced odds of reporting indifference to the BLM movement for U.S.-born Asian Americans only. On the other hand, household income was only significantly associated with indifference to the BLM movement for foreign-born Asian Americans only. For foreign-born Asian Americans, individuals who have less than $\$ 100,000$ household income were more likely to report indifference to the BLM movement while controlling for other characteristics.

\section{Conclusions}

With the ongoing parallel pandemics of historically embedded racism and nativism, important dialogues are emerging to assess the omnipresent nature of White supremacy and its multiply interconnected mechanisms to maintain its status quo by dividing communities along the lines of race and perceived in-group status. In particular, in working toward racial harmony and social justice, the role of immigration has emerged as a critical area of inquiry as non-White immigrants are often accused of being simultaneously marginalized through racialization yet perpetuating anti-Black racism. To assess the role of immigration in White supremacy and systemic racism, the current study examined the individual-level predictors of reporting indifference to the BLM movement by nativity status among Asian Americans-a racialized pan-ethnic group that is comprised of predominantly foreign-born members-using one of the first nationally representative surveys on BLM. In doing so, we first documented that Asian Americans have the highest percentage (42.5\%) of reporting indifference to the BLM movement compared to all other racialized groups. We offered three interrelated hypotheses to inquire what contributes to Asian Americans feeling indifferent to the BLM movement.

First, we hypothesized that Asian Americans' collective odds of reporting indifference to the BLM movement differed by nativity. Consistent with this hypothesis, we identified a clear difference in Asian Americans' indifference to the BLM movement by nativity where foreign-born Asian Americans were 19 percent more likely to report indifference to the BLM movement compared to their U.S.-born Asian American counterparts. This nativity difference is similar to other forms of political participation of Asian Americans where it was found that foreign-born Asian Americans are less likely to engage in both formal and informal political participation (Ramakrishnan and Espenshade 2001; Wong et al. 2011).

Second, we hypothesized that higher belonging was associated with the lower collective odds of reporting indifference to the BLM movement for Asian Americans, regardless of nativity. Our results partially support this hypothesis. They confirmed the second hypothesis in that a higher sense of belonging is associated with the lower collective odds of reporting indifference to the BLM movement while controlling for different identities and citizenship status. This finding is consistent with previous research on how a stronger 
emotional connection to a place is associated with a sense of ownership and leads to greater politics of belonging (Antonsich 2010; Crowley 1999). The independent significance of belonging, apart from different identities, affirms that belonging is a multidimensional concept that is distinct from racial and ethnic identity and citizenship (Antonsich 2010), and is a critical construct to consider in understanding Asian American's perceptions and experiences in future inquires.

Additionally, we found that a sense of belonging was significantly higher for U.S.-born Asian Americans compared to their foreign-born Asian American counterparts, and it was a significant factor predicting the indifference to the BLM movement among U.S.-born Asian Americans only. Although it is beyond the scope of the current study, this finding calls for careful attention to two important nuances for future research. It is important to note that Asian Americans, regardless of nativity status, have the lowest sense of belonging compared to all other racialized groups-even compared to Hispanic/Latinx people who also have a large number of foreign-born group members. We suggest that future research should interrogate the meanings, effects, and mechanisms of belonging among Asian Americans. In particular, lacking a sense of belonging among Asian Americans may be a proxy for the ways Asian Americans potentially internalize racist nativism and feel alienated from the decision-making process in the United States. Moreover, a significantly lower sense of belonging among foreign-born Asian Americans highlights the multidimensional nature of immigrant integration and inclusion. That is, apart from legal inclusion through citizenship, we must consider systemic ways to promote meaningful affective and culture inclusions (Ong et al. 1996). Although it is beyond the scope of this study, we are aware that a sense of belonging through both affective ties to the nation and a sense of inclusion can differ with regard to race/ethnic/class stratifications and nation state governmentality for Asian immigrants and Asian Americans (e.g., East Asians and Vietnamese Chinese compared to Southeast Asians).

Third, we hypothesized that knowledge and explicit acknowledgement of racism in the United States was associated with lower collective odds of reporting indifference to the BLM movement for Asian Americans, regardless of nativity. Our results supported this hypothesis: the acknowledgement of anti-Black racism was associated with significantly reduced odds of reporting indifference to the BLM movement among both foreign-born and U.S.-born Asian Americans. Furthermore, the results were consistent with previous research highlighting the importance of experiences of one's own discrimination in Asian Americans' political participation (Ramakrishnan and Espenshade 2001; Wong et al. 2011). Instead of taking defensive actions and embracing colorblind ideologies from racial stress (DiAngelo 2018), Asian Americans who explicitly acknowledged that there is a lot of racial discrimination against Black Americans were less likely to report indifference to the BLM movement.

While both the acknowledgement of anti-Black racism and one's own discrimination experiences were significant for both groups, foreign-born Asian Americans reported significantly lower levels for both compared to their U.S.-born counterparts. It is plausible that despite rampant yet possibly covert anti-Black racism in Asia (Kim 2015; Kim and Jung 2019; Kwon 2017), foreign-born Asian Americans may have less understanding of racial relations in the localized U.S. context than their U.S.-born counterparts. However, we need more nuanced and careful future research on whether and how anti-Black racism operates differently in the U.S. context versus the transnational context, as well as how the process of international migration may change immigrants' preconceived anti-Black racism. Such efforts must include the development of more robust measurements for assessing the multidimensional experiences of discrimination at the intersection of multiple marginalizations. These efforts would advance our understanding of how immigration intersects with White supremacy leading to political indifference among Asian Americans by elucidating the specific mechanisms (e.g., yellow fragility, linked fate, etc.) (Merseth 2018).

There are a few limitations. First, because the study utilized the cross-sectional design, we cannot make causal claims about the associations among indifference to the BLM movement, nativity, belonging, and acknowledgement of anti-Black racism. Second, 
we acknowledge the limitation of single-item measures for the key constructs. We urge future research to develop and test multidimensional measures assessing racial attitudes, racial consciousness, and discrimination experiences-including the development and testing of the "indifference" measure. Lastly, future studies should include other key measures that are relevant for Asian Americans, including but not limited to: immigration generational status; legal status (e.g., undocumented and liminal legal statuses); and emotional transnationalism (i.e., the psychological experience associated with transnational cultural practices) (Erdal and Oeppen 2013; Ho 2008).

Despite these limitations, the current study has made several contributions. We assessed Asian Americans' indifference to the BLM movement rather than of support or opposition to it. While such indifference is often assumed value-neutral, we discussed the important ways indifference represents a form of anti-Black racism. Thus, indifference may be an intentional choice made through social relation to claim a solitude that can provide certain protections and freedoms afforded by privileges (Simmel [1903] 1997; Tonkiss 2003; Young 2011). We strongly suggest that future research conceptualize and interrogate the meanings of indifference as a specific kind of active dissociation that reproduces anti-Black violence and complicity to White supremacy (Kendi 2019; Liu 2018), especially for Asian Americans. A critical assessment of the meanings of indifference for Asian Americans is particularly important. Indifference to the BLM movement may reflect ambivalenceconflicting feelings from simultaneous investment and contempt for American liberalism. It may also reflect a survival mechanism to secure "relative social peace" in the system of racial capitalism (Simmel [1903] 1997; Tonkiss 2003). We also introduced belonging as the potential concept-distinct from identity and citizenship — for better understanding of how Asian Americans understand, navigate, embody, and reproduce White supremacy. The concept of belonging not only hints at a possible mechanism of how Asian Americans navigate White supremacy (e.g., internalized racist nativism), but also has policy implications on immigrant integration through meaningful affective and culture inclusions. As we call for future research to interrogate the meanings, effects, and mechanisms of belonging, we also offer a caution in conceptualizing belonging as meaningful inclusion. We must first carefully reflect on what it means to belong to the U.S. settler state and how Asian Americans can be in solidarity with Indigenous peoples (Sharma 2020).

Asian Americans are at a critical time point for racial reckoning (Lee 2020). With the complex history of racism and racist nativism that shape the rapid demographic shifts among multiple axes within the United States, Asian Americans must mindfully and intentionally engage in difficult conversations about racial sense making and reflect on their own positionalities as they strive for racial harmony and social justice. Toward this effort, we posit that it is critical to reflect on and reject the ways White supremacy affects Asian Americans (e.g., internalized oppression) (Tran et al. 2018). Furthermore, Asian Americans must simultaneously acknowledge the ways they have participated and benefited from White supremacy and work toward eliminating systemic racism within and across communities. Undoubtedly, the racial reckoning of Asian America has implications for understanding how White supremacy translates to anti-Black racism through multiple interconnected mechanisms for the maintenance of White supremacy (Bonilla-Silva 2001).

Author Contributions: Conceptualization, A.J.Y.H.; methodology, A.J.Y.H.; software, A.J.Y.H.; validation, A.J.Y.H.; formal analysis, A.J.Y.H.; investigation, A.J.Y.H.; resources, A.J.Y.H. and E.D.V.; data curation, A.J.Y.H. and E.D.V.; writing—original draft preparation, A.J.Y.H.; writing-review and editing, A.J.Y.H., K.K., E.K.S. and E.D.V.; visualization, A.J.Y.H.; supervision, A.J.Y.H.; project administration, A.J.Y.H. All authors have read and agreed to the published version of the manuscript.

Funding: This research received no external funding.

Institutional Review Board Statement: This study was approved by the Institutional Review Board of the University of California at Los Angeles (IRB \#16-001799).

Informed Consent Statement: Not applicable. 


\section{Data Availability Statement: Not applicable.}

Acknowledgments: Authors would like to thank Eric Tang for his thoughtful and constructive feedback from the presentation from the annual meeting at the Association for Asian American Studies in 2021.

Conflicts of Interest: The authors declare no conflict of interest.

\section{References}

Abelmann, Nancy, and John Lie. 1997. Blue Dreams: Korean Americans and the Los Angeles Riots. Cambridge: Harvard University Press. Allport, Gordon W. 1954. The Nature of Prejudice. Reading: Addison-Wesley.

Antonsich, Marco. 2010. Searching for belonging-An analytical framework. Geography Compass 4: 644-59. [CrossRef]

Barreto, Matt A., Lorrie Frasure-Yokley, Edward D. Vargas, and Janelle Wong. 2018. Best practices in collecting online data with Asian, Black, Latino, and White respondents: Evidence from the 2016 Collaborative Multiracial Post-election Survey. Politics, Groups, and Identities 6: 171-80. [CrossRef]

Barreto, Matt A., Lorrie Frasure-Yokley, Edward D. Vargas, and Janelle Wong. 2017. The Collaborative Multiracial Post-Election Survey (CMPS), 2016. Los Angeles: CMPS.

Boggs, Grace Lee. 2016. Living for Change: An Autobiography. Minneapolis: University of Minnesota Press.

Bonilla-Silva, Eduardo. 2001. White Supremacy and Racism in the Post-Civil Rights Era. Boulder: Lynne Rienner Publishers.

Bonilla-Silva, Eduardo. 2004. From bi-racial to tri-racial: Towards a new system of racial stratification in the USA. Ethnic and Racial Studies 27: 931-50. [CrossRef]

Bottero, Wendy. 2010. Intersubjectivity and Bourdieusian approaches to 'identity'. Cultural Sociology 4: 3-22. [CrossRef]

Buchanan, Larry, Quoctrung Bui, and Jugal K. Patel. 2020. Black Lives Matter May Be the Larges Movement in U.S. History. New York: The New York Times. Available online: https://www.nytimes.com/interactive/2020/07/03/us/george-floyd-protests-crowdsize.html (accessed on 16 August 2020).

Chang, Edward T. 2004. “As Los Angeles Burned, Korean America was Born” Community in the Twenty-first Century. Amerasia Journal 30: vi-x. [CrossRef]

Cheng, Wendy. 2013. Strategic orientalism: Racial capitalism and the problem of 'Asianness'. African Identities 11: 148-58. [CrossRef]

Chin, Margaret M. 2020. Stuck: Why Asian Americans Don't Reach the Top of the Corporate Ladder. New York: NYU Press.

Clark, Amanda D., Prentiss A. Dantzler, and Ashley E. Nickels. 2018. Black lives matter: (Re)framing the next wave of black liberation. In Research in Social Movements, Conflicts and Change. Edited by Patrick G. Coy. Somerville: Emerald Publishing.

Collins, Patricia Hill. 1990. Black Feminist Thought: Knowledge, Consciousness, and the Politics of Empowerment. London: Routledge.

Crenshaw, Kimberlé. 1990. Mapping the margins: Intersectionality, identity politics, and violence against women of color. In Critical Race Theory: The Key Writings that Formed the Movement. Edited by Kimberlé Crenshaw, Neil Gotanda, Gray Peller and Kendall Thomas. New York: New Press, pp. 357-83.

Crenshaw, Kimberlé, Priscilla Ocen, and Jyoti Nanda. 2015. Black Girls Matter: Pushed Out, Overpoliced, and Underprotected. New York: Center for Intersectionality and Social Policy Studies, Columbia University.

Crowley, John. 1999. The politics of belonging: Some theoretical considerations. In The Politics of Belonging: Migrants and Minorities in Contemporary Europe. Edited by Andrew Geddes and Adrian Favell. Aldershot: Ashgate, pp. 15-41.

Davis, Angela Y. 2016. Freedom Is a Constant Struggle: Ferguson, Palestine, and the Foundations of a Movement. Chicago: Haymarket Books.

Della Porta, Donatella. 2013. Can Democracy Be Saved?: Participation, Deliberation and Social Movements. Hoboken: John Wiley \& Sons.

DiAngelo, Robin. 2018. White Fragility: Why It's so Hard for White People to Talk about Racism. Boston: Beacon Press.

Dimock, Michael. 2019. Defining Generations: Where Millennials End and Generation Z Begins. Washington, DC: Pew Research Center. Available online: https://www.pewresearch.org/fact-tank/2019/01/17/where-millennials-end-and-generation-zbegins / (accessed on 16 August 2020).

Ebert, Kim, and Dina Okamoto. 2015. Legitimating contexts, immigrant power, and exclusionary actions. Social Problems 62: 40-67. [CrossRef]

Erdal, Marta Bivand, and Ceri Oeppen. 2013. Migrant balancing acts: Understanding the interactions between integration and transnationalism. Journal of Ethnic and Migration Studies 39: 867-84. [CrossRef]

Espiritu, Yen Le. 1993. Asian American Panethnicity: Bridging Institutions and Identities. Philadelphia: Temple University Press.

Fortier, Anne-Marie. 2000. Migrant Belongings: Memory, Space, Identity. London: Routledge.

Fujino, Diane Carol. 2005. Heartbeat of Struggle: The Revolutionary Life of Yuri Kochiyama. Minneapolis: University of Minnesota Press.

Garcia, Marc A., Patricia A. Homan, Catherine García, and Tyson H. Brown. 2020. The color of COVID-19: Structural racism and the pandemic's disproportionate impact on older racial and ethnic minorities. The Journals of Gerontology: Series B 76: e75-e80. [CrossRef]

Gold, Steven J. 2004. From Jim Crow to racial hegemony: Evolving explanations of racial hierarchy. Ethnic and Racial Studies 27: 951-68. [CrossRef]

Ho, Elaine Lynn-Ee. 2008. Citizenship, migration and transnationalism: A review and critical interventions. Geography Compass 2: 1286-300. [CrossRef]

Ho, Jennifer. 2020. Anti-Asian racism, Black Lives Matter, and COVID-19. Japan Forum 3: 148-59. [CrossRef] 
Hollinger, David A. 2000. Postethnic America: Beyond Multiculturalism. New York: Basic Books.

Hong, Cathy P. 2020. Minor Feelings: An Asian American Reckoning. New York: One World.

Hope, Jeanelle K. 2019. This tree needs water!: A case study on the radical potential of Afro-Asian solidarity in the era of Black Lives Matter. Amerasia Journal 45: 222-37. [CrossRef]

Horowitz, Juliana M., and Gretchen Livingston. 2016. How Americans View the Black Lives Matter Movement. Washington, DC: Pew Research Center. Available online: https:/ / www.pewresearch.org/fact-tank/2016/07/08/how-americans-view-the-blacklives-matter-movement/ (accessed on 16 August 2020).

Johnson, David R., and Rebekah Young. 2011. Toward best practices in analyzing datasets with missing data: Comparisons and recommendations. Journal of Marriage and Family 73: 926-45. [CrossRef]

Kampmark, Binoy. 2020. Protesting in pandemic times: COVID-19, public health, and Black Lives Matter. Contention 8: 1-20. [CrossRef]

Kao, Grace. 2006. Where are the Asian and Hispanic victims of Katrina?: A metaphor for invisible minorities in contemporary racial discourse. Du Bois Review 3: 223-31. [CrossRef]

Kendi, Ibram X. 2019. How to be An Antiracist. New York: Random House.

Khan-Cullors, Patrisse. 2018. When They Call You a Terrorist: A Black Lives Matter Memoir. New York: St. Martin's Press.

Kim, Claire Jean. 1999. The racial triangulation of Asian Americans. Politics E Society 27: 105-38.

Kim, Clare Jean, and Taeku Lee. 2001. Interracial politics: Asian Americans and other communities of color. Political Science and Politics 34: 631-37. [CrossRef]

Kim, Elaine H. 1993. Home is where the han is: A Korean American perspective on the Los Angeles upheavals. Social Justice 20: 1-21.

Kim, Jae Kyun. 2015. Yellow over black: History of race in Korea and the new study of race and empire. Critical Sociology 41: 205-17. [CrossRef]

Kim, Jae Kyun, and Moon-Kie Jung. 2019. “The Darker to the Lighter Races": The Precolonial Construction of Racial Inferiors in Korea. History of the Present 9: 55-83. [CrossRef]

Kim, Nadia. 2007. Asian Americans' experiences of "race" and racism. In Handbooks of the Sociology of Racial and Ethnic Relations. Edited by Hernán Vera and Joe R. Feagin. New York: Springer, pp. 131-44.

Kochiyama, Yuri. 1994. The impact of Malcolm X on Asian-American politics and activism. In Blacks, Latinos, and Asians in Urban America: Status and Prospects for Politics and Activism. Edited by James Jennings. Westport: Greenwood Publishing Group, pp. 129-41.

Kuo, Wen H. 1995. Coping with racial discrimination: The case of Asian Americans. Ethnic and Racial Studies 18: 109-27. [CrossRef]

Kwon, Yaejoon. 2017. Transcolonial racial formation: Constructing the "Irish of the Orient" in US-occupied Korea. Sociology of Race and Ethnicity 3: 268-81. [CrossRef]

Lee, Erika. 2015. The making of Asian America: A History. New York: Simon and Schuster.

Lee, Jennifer C. 2020. The nativist fault line and precariousness of race in the time of Coronavirus. ASA Footnotes 48: 17.

Lee, Jennifer C., and Samuel Kye. 2016. Racialized assimilation of Asian Americans. Annual Review of Sociology 42: 253-73. [CrossRef]

Leong, Nancy. 2013. Racial Capitalism. Harvard Law Review 126: 2151-226. [CrossRef]

Lien, Pei-te, M. Margaret Conway, and Janelle Wong. 2004. The Politics of Asian Americans: Diversity and Community. London: Routledge.

Lipsitz, George. 1995. The possessive investment in whiteness: Racialized social democracy and the" white" problem in American studies. American Quarterly 47: 369-87. [CrossRef]

Liu, Wen. 2018. Complicity and resistance: Asian American body politics in Black Lives Matter. Journal of Asian American Studies 21: 421-51. [CrossRef]

López, Ian H. 1997. White by Law: The Legal Construction of Race. New York: NYU Press.

Maeda, Daryl J. 2009. Chains of Babylon: The Rise of Asian America. Minneapolis: University of Minnesota Press.

Matsuda, Mari. 1993. We will not be used. UCLA Asian Pacific American Law Journal 1: 79.

May, Vanessa. 2011. Self, belonging and social change. Sociology 45: 363-78. [CrossRef]

McGary, Howard. 1997. Racism, social justice, and interracial coalitions. The Journal of Ethics 1: 249-64. [CrossRef]

Merseth, Julie Lee. 2018. Race-ing solidarity: Asian Americans and support for Black Lives Matter. Politics, Groups, and Identities 6: 337-56. [CrossRef]

Milbrath, Lester W., and Madan Lal Goel. 1977. Political Participation: How and Why Do People Get Involved in Politics? Chicago: Rand McNally College Publishing Company.

Nopper, Tamara K. 2006. The 1992 Los Angeles riots and the Asian American abandonment narrative as political fiction. The New Centennial Review 6: 73-110. [CrossRef]

O'Reilly, Kevin B. 2020. American Medical Association: Racism is a Threat to Public Health. Chicago: American Medical Association. Available online: https://www.ama-assn.org/delivering-care/health-equity/ama-racism-threat-public-health (accessed on 30 November 2020).

Okamoto, Dina G. 2003. Toward a theory of panethnicity: Explaining Asian American collective action. American Sociological Review 1: 811-42. [CrossRef]

Okamoto, Dina G. 2014. Redefining Race: Asian American Panethnicity and Shifting Ethnic Boundaries. New York: Russell Sage Foundation. Omi, Michael, and Howard Winant. 1994. Racial Formation in the United States: From the 1960s to the 1990s. New York: Routledge. 
Ong, Aihwa, Virginia R. Dominguez, Jonathan Friedman, Nina Glick Schiller, Verena Stolcke, David Y.H. Wu, and Hu Ying. 1996. Cultural citizenship as subject-making: Immigrants negotiate racial and cultural boundaries in the United States. Current Anthropology 37: 737-62. [CrossRef]

Parker, Kim, Juliana Menasce Horowitz, and Monica Anderson. 2020. Amid Protests, Majorities Across Racial and Ethnic Groups Express Support for the Black Lives Matter Movement. Washington, DC: Pew Research Center. Available online: https:/ / www.pewresearch.org/social-trends/2020/06/12/amid-protests-majorities-across-racial-and-ethnic-groups-expresssupport-for-the-black-lives-matter-movement/ (accessed on 16 August 2020).

Perea, Juan F. 1998. The Black/White binary paradigm of race: The normal science of American racial thought. La Raza Law Journal 10: 127-72. [CrossRef]

Pettigrew, Thomas F. 1998. Intergroup contact theory. Annual Review of Psychology 49: 65-85. [CrossRef]

Pirtle, Whitney N. Laster. 2020. Racial capitalism: A fundamental cause of novel coronavirus (COVID-19) pandemic inequities in the United States. Health Education \& Behavior 47: 504-8.

Ramakrishnan, S. Karthick, and Thomas J. Espenshade. 2001. Immigrant incorporation and political participation in the United States. International Migration Review 35: 870-909. [CrossRef]

Sharma, Nandita. 2020. Home Rule: National Sovereignty and the Separation of Natives and Migrants. Durham: Duke University Press.

Simmel, Georg. 1997. The Metropolis and Mental Life. In Simmel on Culture. Edited by David Frisby and Mike Featherstone. London: Sage, pp. 174-85. First published 1903.

Simon, Bernd, and Bert Klandermans. 2001. Politicized collective identity: A social psychological analysis. American Psychologist 56: 319-31. [CrossRef]

Skrentny, John David. 2001. Color Lines: Affirmative Action, Immigration, and Civil Rights Options for America. Chicago: University of Chicago Press.

Smith, Andrea. 2012. Indigeneity, Settler Colonialism and White Supremacy. In Racial Formation in the Twenty-First Century. Edited by Daniel Martinez HoSang, Oneka LaBennett and Laura Pulido. Berkeley: University of California Press, pp. 66-94.

Takaki, Roland. 1993. A Different Mirror: A History of Multicultural America. New York: Back Bay Books.

Thomas, Deja, and Juliana Menasce Horowitz. 2020. Support for Black Lives Matter Has Decreased since June but Remains Strong among Black Americans. Washington, DC: Pew Research Center. Available online: https://www.pewresearch.org/fact-tank/2020 /09/16/support-for-black-lives-matter-has-decreased-since-june-but-remains-strong-among-black-americans / (accessed on 30 November 2020).

Thomas, Emma F., Elena Zubielevitch, Chris G. Sibley, and Danny Osborne. 2020. Testing the social identity model of collective action longitudinally and across structurally disadvantaged and advantaged groups. Personality and Social Psychology Bulletin 46: 823-38. [CrossRef]

Tonkiss, Fran. 2003. The Ethics of Indifference: Community and Solitude in the City. International Journal of Cultural Studies 6: 297-311. [CrossRef]

Tran, Nellie, Nadine Nakamura, Grace S. Kim, Gagan S. Khera, and Julie M. AhnAllen. 2018. APIsforBlackLives: Unpacking the interracial discourse on the Asian American Pacific Islander and Black communities. Community Psychology in Global Perspective 4: 73-84.

U.S. Census Bureau. 1960. Census 1960; Washington, DC: U.S. Census Bureau.

U.S. Census Bureau. 2020. 2014-2018 American Community Survey 5-Year Estimates; Washington, DC: U.S. Census Bureau.

Van Zomeren, Martijn, Tom Postmes, and Russell Spears. 2008. Toward an integrative social identity model of collective action: A quantitative research synthesis of three socio-psychological perspectives. Psychological Bulletin 134: 504-35. [CrossRef]

West, C. 1993. Race Matters. Boston: Beacon Press.

Wiley, Shaun, and Nida Bikmen. 2012. Building solidarity across difference: Social identity, intersectionality, and collective action for social change. In Social Categories in Everyday Experiences. Edited by Shaun Wiley, Gina Philogène and Tracey A. Revenson. Washington, DC: American Psychological Association.

Wong, Janelle. S., S. Karthick Ramakrishnan, Taeku Lee, and Jane Junn. 2011. Asian American Political Participation: Emerging Constituents and Their Political Identities. New York: Russell Sage Foundation.

Wu, Ellen D. 2013. The Color of Success: Asian Americans and the Origins of the Model Minority. Princeton: Princeton University Press.

$\mathrm{Xu}$, Jun. 2005. Why do minorities participate less? The effects of immigration, education, and electoral process on Asian American voter registration and turnout. Social Science Research 34: 682-702. [CrossRef]

$\mathrm{Xu}$, Jun, and Jennifer C. Lee. 2013. The marginalized "model" minority: An empirical examination of the racial triangulation of Asian Americans. Social Forces 91: 1363-97. [CrossRef]

Yancey, George A. 2003. Who is White? Latinos, Asians, and the New Black/Nonblack Divide. Boulder: Lynne Rienner Publishers.

Young, Iris Marion. 2011. Justice and the Politics of Difference. Princeton: Princeton University Press.

Zhou, Min, and Jennifer Lee. 2017. Hyper-selectivity and the remaking of culture: Understanding the Asian American achievement paradox. Asian American Journal of Psychology 8: 7-15. [CrossRef]

Zia, Helen. 2000. Asian American Dreams: The Emergence of an American People. New York: Farrar, Straus, \& Giroux. 